\title{
Neurodegenerative Diseases and Stem Cell Transplantation
}

\section{Renald Blundell and Munirih Shah*}

Physiology and Biochemistry, Faculty of Medicine and Surgery, University of Malta, Malta

\begin{abstract}
Stem cells can simply be defined as cells that possess differentiation potential and the ability to self-renew. Since their discovery research in this area has continued to increase. One of the main reasons for this is due to the high potential they have in treating illness and disease. It was initially thought that neurons were unable to be replaced. However, there is now much research indicating that the process of neurogenesis does take place in the brain. This therefore has spurred on much research to see the role that stem cells have to play in treating neurodegenerative diseases, which are characterized by the loss of neuron and glia. If we are able to find a way through the use of stem cells to replace lost neurons and glia we would be well on the way to finding a cure for many neurodegenerative diseases.
\end{abstract}

This review will look at four main types of neurodegenerative disease: Parkinson's disease, Huntington's chorea, Multiple Sclerosis and Alzheimer's. The pathology and known underlying causes will be discussed, followed by current treatments and finally a review of the current evidence there is for the role of stem cells in treating these neurodegenerative disorders.

Keywords: Stem cells; Neurodegenerative diseases; Parkinsons's disease; Neurogenesis; Treatment

Abbreviations: AD: Alzheimer's Disease; ASCs: Adult Stem Cells; BDNF: Brain Derived Neurotrophic Factor; CNS: Central Nervous System; ESCs: Embryonic Stem Cells; FGF-2: Fibroblast Growth Factor 2: HD: Huntington's Disease; HSCs: Haematopoietic Stem Cells; IBMX: 3-Isobutyl-1-methylxanthine; L-DOPA: L-dihydroxyphenyl alanine; MPTP: 1-methyl-4phenyl-1, 2,3,6 tetrahydropyridine; MS: Multiple Sclerosis; MSCs: Mesenchymal Stem Cells; PD: Parkinson's Disease

\section{Introduction}

In the mid 1800's cells were discovered to be the building blocks of life. It was then later discovered that in addition to this simple role, some cells were found to have the ability to self-renew and proliferate. We now refer to these cells more commonly as stem cells, this term being coined for use in the scientific world by histologist Alexander Maksimov in 1908 [1].

As research in this field of stem cells progressed Ramon y Cajal, known to many as the father of Neuroscience, made a profound statement affirming: 'In adult centres the nerve paths are something fixed, ended, immutable. Everything may die, nothing may be regenerated. However, since this statement there is much evidence that has proved it to be inaccurate, as in fact encouraged by Cajal himself: 'It is for the science of the future to change, if possible, this harsh decree.'

Altman and Das carried one of the earliest studies In 1965 that disproved Cajal's statement, but unfortunately was not given much attention, In this study rats were injected with thymidine- $\mathrm{H} 3$ resulting in a great number of the granule cells of the dentate gyrus being labeled. As the rat aged from the time the injection was given, the number of labeled granule cells was found to decrease. On further analysis it was found that the cells, which were undifferentiated and in close proximity to the granular layer of the dentate gyrus displayed a fast rise in number which was then followed by a decline. This decline in undifferentiated cells was found to occur simultaneously to the increase in differentiated cells. From the study they concluded that undifferentiated cells postnatal move towards the hippocampus from the forebrain ventricles, where they go on to differentiate [2]. This study was one of the earliest experiments showing evidence for the occurrence of neurogenesis.
A more recent case showing evidence of neurogenesis was in a patient who was minimally conscious for 19 years. Overtime he showed improvements in his speech and language. Through the use of PET and MRI scans central nervous system (CNS) remodeling and axonal growth could be seen [3]. As time progressed more evidence was shown that stem cells do exist and could be obtained from a variety of sources.

The next obstacle to overcome was to create pluripotent stem cell lines. This was achieved in 1998 when the first embryonic stem cell line was developed from cells isolated from the inner cell mass of early embryos. These cells were described to manifest elevated levels of telomerase activity, have regular karyotypes, and express cell surface markers that are characteristics of early primate embryonic stem cells (ESCs) but no other early cell lineages. These cells underwent undifferentiated cell proliferation for approximately 4 to 5 months and were still able to mature into trophoblasts and derivatives of endoderm, mesoderm and ectoderm [4].

During that same year research was undertaken involving primordial germ cells extracted from mesenteries and gonadal ridges. These primordial germ cells were cultured and found to grow into large multicellular colonies that resembled pluripotent stem cells known as embryonic stem and embryonic germ cells. They were found to have the characteristics pluripotent stem cells should have, closely resembling embryonic germ cells: throughout culture they remained alkaline phosphate positive and they were positive for 5 immunological markers that characterize embryonic stem and embryonic germ cells. Furthermore they were found to have normal karyotypes and be stable, in addition to revealing a wide variety of different cell types, inclusive of the three embryonic germ layers [5]. These two early experiments

*Corresponding author: Munirih Shah, Phyisology and Biochemistry, Faculty of Medicine and Surgery, Room 126, Biomedical Sciences Building, University of Malta, MSD 2080, Malta, Tel: 00356 99928928; E-mail: munirih.shah.12@um.edu.mt

Received March 16, 2015; Accepted April 17, 2015; Published April 19, 2015

Citation: Blundell R, Shah M (2015) Neurodegenerative Diseases and Stem Cell Transplantation. J Stem Cell Res Ther 5: 277. doi:10.4172/2157-7633.1000277

Copyright: (c) 2015 Blundell R, et al. This is an open-access article distributed under the terms of the Creative Commons Attribution License, which permits unrestricted use, distribution, and reproduction in any medium, provided the original author and source are credited. 
showed great hope for future research into stem cell differentiation and cell proliferation.

The interest in stem cells has continued to grow. One of the main reasons for this is the great potential they have to contribute to the progress of Medicine. For example, they have so far shown potential in the involvement of bone marrow transplants in immunodeficient diseases. In 1963 the presence of self-renewing cells were found within the bone marrow of mice. Normal mouse blood-forming tissues were found to contain a class of cell which, when placed into heavily irradiated mice were able to proliferate and become macroscopic colonies in the spleen [6]. 5 years following this marked one of the first successful bone marrow transplants where a 5-month-old male suffering from sex-linked lymphopenic immunological deficiency was treated with immunologically competent cells obtained from peripheral blood buffy coat and bone marrow of a sibling donor. The result of this was a return of cellular and humoral immunity in the 5-month-old patient [7].

In addition to bone marrow transplants, stem cells have also shown great potential for organ transplantations. Transplantation medicine was pioneered when the first electrophysiological experiments were able to develop cardiomyocytes from ESCs [8].

Another field where stem cells are showing great advancements is in the treatment of neurodegenerative disorders, which are characteristic of loss of neurons and glia. Amongst all the organs, the CNS shows the most difficulty in regeneration [9]. Despite this, there is now promising research that indicates it is possible to regenerate the cells of the CNS using stem cells. New migrating stem cells have been found within the brains of rodent models with induced injury. Furthermore, cells derived from the bone marrow have been found to have the ability to develop into cells with neuronal and vascular phenotype to help in repair of brain injury. Neural stem cells (NSCs) have also been found to be of clinical importance because they can migrate and hone towards distant areas. They are able to differentiation into neurons and glia and in addition to this they are able to rescue injured and dysfunctional endogenous neurons, serving as chaperones [10]. Therefore, it can be seen that stem cells from a number of sources are now showing great potential in the treatment of neurodegenerative diseases.

\section{Stem Cells}

As a multicellular organism develops, the cells undergo a sequence of programmed events that result in them becoming differentiated, forming organs and tissues that make up an adult individual. The majority of cells go through this process. However there are a number of cells that do not take place in this developmental process but rather become reserved precursor cells. These precursor cells can be separated into two main categories: lineage-committed progenitor cells and lineage uncommitted pluripotent stem cells.

There is often ambiguity of what exactly defines a stem cell. A minimalist definition describes stem cells as cells that have the ability to self-renew and have the ability to produce differentiated progeny in order to help maintain and repair the tissues and organs throughout an individual's life, a term known as pluripotency [11].

Self-renewal involves division of the cell through the process of mitosis and maintenance of its pluripotent property. Selfrenewal is of two types: asymmetrical and symmetrical. The ESCs divide to form two cells of equal identity whilst adult stem cells (ASCs) divide forming a stem cell and a progenitor cell [12]. Stem cells having the property of pluripotency mean they have the ability to differentiate into derivatives of ectoderm, mesoderm and endoderm, totalling to a number of 200 different kinds of cells [12].
In addition to these two main properties stem cells are also able to: differentiate, renew them, migrate and distribute within the CNS once implanted, proliferate, be obtained from the patients, be easily manipulated using viral and non-viral gene transfer methods and integrate into the cell structure of the brain showing potential of regulated release of substances [13].

These properties of stem cells are very attractive when it comes to finding a treatment for neurodegenerative diseases: those characteristic of loss of neurons and glia. If we can find a way to renew and differentiate cells those lost neurons and glia then we would be well on the way to finding a cure. There are three main sources of where stem cells can be obtained: embryonic, adult and umbilical stem cells.

\section{Embryonic Stem Cells (ESCs)}

ESCs are obtained from the inner cell mass of the blastocyst and 'embryonic germ cells have been obtained from post-implantational embryos' [13]. ESCs are uncommitted cells and the progenitors of the three embryonic germ cell layers: endoderm, ectoderm, and mesoderm. Therefore they are able to give rise to all the germ line and somatic cells of developed organisms [14].

One of the main limitations of the use of ESCs is in the moral and ethical complications surrounding their origin [15]. Furthermore, it has been found that human ESCs give rise to teratomas meaning that they are limited in their use for therapeutic treatment [12].

Fetal stem cells also have ethical issues surrounding them but less so ESCs. They are obtained from fetal blood and bone marrow in addition to liver and kidney tissue. Within the fetal blood are a large supply of haematopoietic stem cells (HSCs) and mesenchymal stem cells (MSCs) [16].

\section{Adult Stem Cells (ASCs)}

ASCs have been found to be present within many of the tissues and organs within the human body. Compared to ESCs, ASCs are more limited in renewal and differentiation. Their renewal and differentiation is usually found to be limited to the cells of the tissue in which they are found. When they are able to generate cells from a different tissue to their origin, it is referred to as transdifferentiation [12]. For example, HSCs have been found to travel to the brain and differentiate into neuron-like cells [17].

Neural stem cells (NSCs): Present within the adult brain are NSCs, which are able to generate neurons and non-neuronal cells (astrocytes and oligodendrocytes). This process is known as neurogenesis.

NSC's can be found in the subcortical white matter, hippocampus and sub ventricular zone. The subventricular zone is home to the biggest stem cell niche. NSCs present here are found to differentiate into astrocytes. NSC's found in the hippocampus differentiate into neuroblasts which go on to give rise to granule cells [12].

NSC's derived from non-hippocampal regions were expanded in culture using different types of growth factors such as fibroblast growth factors and epidermal growth factors. They were in fact found to be highly expandable, being maintained for 60 population doublings with low occurrence of senescence and no reported immortalising mutations. The amount of cells produced was found to be enough for 4 $\times 10^{7}$ brains. When transferred into rodent brains they took on glial and neuronal phenotypes [10].

Bone marrow derived stem cells: Multipotent stem cells are advantageous over NSCs because they can avoid the risk of having 
to access the brain in order to be obtained. Examples of multipotent stem cells are the mesenchymal stem cells (MSCs). They are obtained from the bone marrow and arise from mesoderm making them easily accessible [18]. MSCs have the ability to differentiate into cartilage, fat, bone and cells supporting the formation of fibrous connective tissue and blood $[19,20]$. They have also been found to be able to differentiate into hepatocytes, cardiac and skeletal muscles well as glial and neurons. Another advantage of multipotent stem cells is they are immunologically inactive. Furthermore, due to autologous transplantation the ethical issues associated with fetal and embryonic stem cells are avoided [18]. Within the bone marrow of adults one can find HSCs, which are able to form all the type of blood cells in the body $[19,20]$.

Induced pluripotent stem cells: Induced pluripotent stem cells (IPSCs) are a recent discovery and are obtained from adult cells. On introduction of four genes, adult cells gained the ability to differentiate into any other cell type. IPSCs are very promising for the treatment of neurodegenerative disease as they have the ability to replace those cells lost and destroyed during the progression of disease. They have been likened to ESCs. However, the advantage that they hold over ESCs is they avoid the ethical issues surrounding how ESCs are obtained [21].

\section{Umbilical Stem Cells}

When newborns are delivered it was always common practice to remove the umbilical cord, but since the umbilical cord was found to be a source of HSCs this is now no longer always the case.

Collecting umbilical stem cells involves collecting blood from the umbilical cord. The stem cells in the blood are then concentrated and preserved in liquid nitrogen at freezing temperatures. This method of preservation enables the cells to be stored for years until needed. The advantage of this is there is no time lost on finding donors. The number of patients treated using stored umbilical stem cells reaches 3000 and spans around 45 different illnesses. There is hope for the use of umbilical stem cells in treating many other pathologies including repair of neurons [22]. The downside of umbilical stem cells is their limited availability [23].

\section{Neurodegenerative Diseases}

The CNS is made up neurons and glial cells; which protect the neurons by surrounding them. An example of a glial cell is the oligodendrocyte whose main function is to increase the time of which neuronal signals are sent over extensive distances. Conditions in which these nerve cells are lost are referred to as neurodegenerative disorders. Much research is going into looking at how these lost nerve cells can be replaced. Neural stem cells hold much promise for this [24].

NSCs have the ability to generate neurons and glia but this only occurs at a few sites within the brain. Therefore much research is being undertaken to find methods and techniques in which stem cells grown in culture can be implanted into patients brain where they are able to differentiate into neurons and glia or finding ways where already differentiated neural and glia cells can be implanted [24].

We will now look at four main types of neurodegenerative diseases: Parkinson's disease, Huntington's disease, Multiple sclerosis and Alzheimer's disease, and see in turn what are their pathogenesis and symptoms, current treatments and the current evidence for the use of stem cells as treatment for these neurodegenerative disorders.

\section{Parkinson's Disease}

Parkinson's disease (PD) affects $1 \%$ of the population by the time they reach the age of 60 and therefore is found to be the most common neurodegenerative movement disorder [25]. It affects mainly motor functions where patients present mainly with tremor, rigidity and cognitive impairment. It is a slowly progressing disease, first affecting the different sides of the body in turn [26].

In this disease, at the cellular level, patients show loss of dopamine neurons present in the substantia nigra pars compact a within the midbrain. There can be observed accumulation of aggregates called Lewy bodies, which cause destruction of neurons $[9,27]$. This disturbance can cause changes to the pattern of firing neurons, for example an increase of: firing, bursting, synchrony and a leaning towards loss of specificity in the receptive fields. This change in the pattern of firing neurons is then conveyed to the thalamus, cortex and brainstem and therefore thought to disturb the way in which the motor system works, thus leadings to the symptoms associated with PD: tremor, rigidity, akinesia [28].

However, the conventional idea that degeneration starts in the substantia nigra is now being questioned. There is evidence showing that there is a spread of alpha synuclein, which starts in the brainstem. From here this then goes to the substantia nigra and involves more of the cortical areas, thus reflecting the clinical progression of PD. One of the first signs of the disease is not one linked to the motor system but rather sleep disturbances, autonomic abnormalities and loss of sense of smell. It is when it involves the substantia nigra you get typical rigidity and bradykinesia. At the end stage is when dementia and high cognitive dementia sets in. This again can be associated with the spread of aggregation inside the brain, which goes on to affect other areas responsible for memory and cognition $[25,29]$.

\section{Current treatment}

One would think that PD would be an easy disorder to treat, as it is loss of just one type of cell population: dopaminergic neurons. However, the research has shown that is proving to be much more difficult.

At the moment there is no definitive treatment for PD but rather management of symptoms mainly through the use of drugs and surgery. As patients suffering from PD suffer from low levels of dopamine they are given a precursor of dopamine: L-dihydroxyphenyl alanine (L-DOPA). A precursor is given, as dopamine is not able to pass across the blood brain barrier. Instead L-DOPA is taken up by the substantia nigra and metabolized to dopamine.

Another treatment used for patients suffering from PD is deep brain stimulation. It has been found that stimulation of the ventral intermediate nucleus of the thalamus can greatly alleviate the symptom of tremor. Other symptoms such as rigidity, bradykinesia and gait difficulties are found to reduce through stimulation of the subthalamic nucleus or the internal segment of the globus pallldius [30].

\section{Stem cell treatment}

Much research has been conducted on aborted fetuses and the stem cells that can be obtained from them. Initially dopaminergic cells were experimented with to see if they could be involved in the treatment of PD. In one study mesencephalic tissue were obtained from human fetuses and grafted into patient's brains. Patients were found to show significant improvement after 6-12 weeks of grafting. Follow up after one year showed patients remained stable and furthermore showed improvement in complex arm movements (Figure 1) [31]. This study showed promising results. However it was based on a sample size of two people.

In another study 6 patients underwent bilateral fetal nigral transplantation. This involved grafts from 6 and a $1 / 2$ to 9 week aborted 
fetuses after conception. Patients were then monitored on how often they presented with dyskinesia (involuntary movement), during half an hour intervals. Results showed that their daily life activities and motor functions improved greatly. In the on phase (moving well) the amount of time without dyskinesia increased showing positive results (Figure 2)

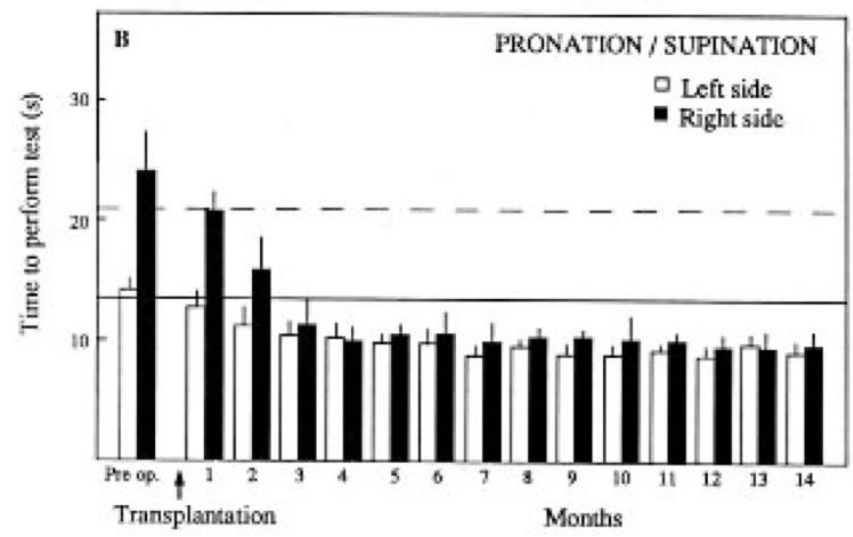

Figure 1: Evidence for the use of mesencephalic tissue in treatment of Parkinson's disease. Patient shows reduction in the time taken to perform complex arm movement following transplantation of mesencephalic tissue [31].
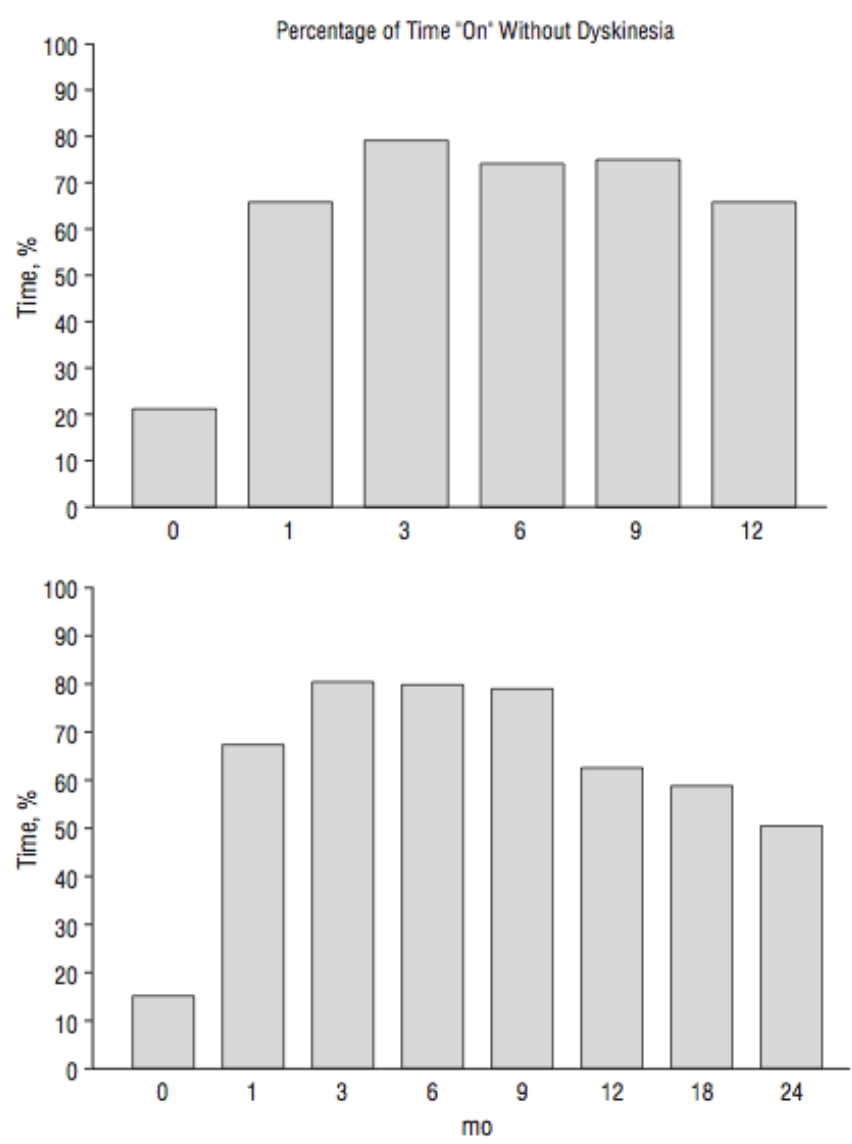

Figure 2: Reported dyskinesia following bilateral fetal nigral transplantation. The top picture shows the mean percentage of time in the 'on' phase without dyskinesia in 6 patients over 12 months. The bottom picture shows the results for 4 patients over 24 months [32].
[32]. A limitation with this study was that again it had a small sample size making it hard to extrapolate the results to a wider population of patients suffering with PD. Furthermore, in Figure 2 you can see that in the patients who were monitored for 24 months the amount of time in the 'on' phase without dyskinesia in fact began to reduce following nine months.

Studies carried out later indicated that in fact that the use of fetal cells was not as effective as these studies had shown. 34 patients were involved in a randomised controlled study. Here some patients received fetal nigral transplantation from either one or four donors whilst others were placed into a placebo group. The results shows that those in the one donor and placebo group in fact showed deterioration whilst those in the four-donor group showed improvement. Furthermore, 56\% of the patients with the transplants when on to develop dyskinesia after overnight withdrawal of medicines. These results meant that fetal nigral transplantation could not be used as a recommended therapy for PD [33].

The use of fetal-derived NSCs have been shown to assist in the treatment of rodent models suffering from PD. Undifferentiated human NSCs were transplanted into 1-methyl-4phenyl-1, 2,3,6-tetrahydropyridine (MPTP) treated primates. The transplanted cells were found to survive, migrate and induce behavioural recovery. Tumorogenicity was also found to be minimal [34].

Much research has taken place on ESCs involvement in the treatment $\mathrm{PD}$. In one study a progenitor population was obtained from ESCs. These cells were then increased and encouraged to differentiate into dopaminergic neurons and serotonergic neurons. Mitogen and specific signaling molecules were used to do this. When the mitogen was withdrawn the differentiation and maturation into neurons continued. These neurons were found to improve PD. A downside was that $20 \%$ of the mice went on to develop teratomas [35]. However a study using Nur1, a transcription factor that participates in the differentiation of dopaminergic cells, showed positive results with no formation of tumors. The dopamine neurons showed the same electrophysiological and behavioral properties as neurons [27]. The limitation of these studies was that the ESCs were derived from mice. Therefore, it makes it difficult to extrapolate the findings to humans.

One study that did use human ESCs involved placing them into the brains of neonatal mice. Initially the human ESCs developed into neural tube-like structure in the presence of FGF-2. The precursors were then isolated using enzymatic digestion and purified depending on differential adhesion. These precursors were then implanted into the mouse brain. They were found to incorporate into various brain regions and become both neurons and glial cells. No teratomas were found to develop [36]. Despite being human ESCs they were still implanted into mice brains making it not possible to extrapolate to humans. Furthermore, the use of ESCs raises a lot of safety and ethical implications.

In one randomised controlled trial a sample of 40 participants, aged 34-75 years suffering from PD, were either given a transplantation of human embryonic dopamine neurons or gives a placebo surgery. Improvements were seen in the younger patients (60 years and below) but no significant improvements were shown in the older patients. In addition to this, follow up after the first year showed recurrence of dyskinesia in $15 \%$ of the patients [37].

In order to avoid the ethical issues associated with the use of ESCs, ASCs have been an attractive therapy to work with as an alternative and have been showing some promising results. In one study MSCs 


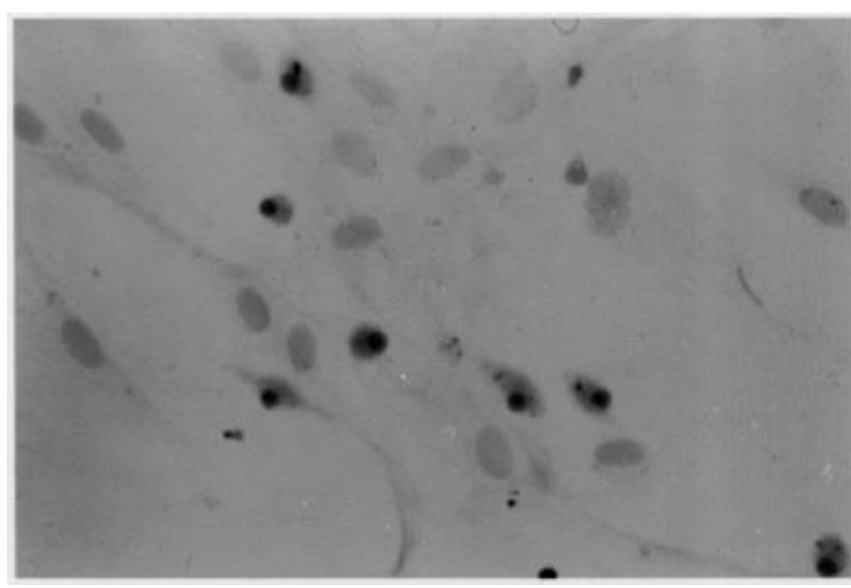

Figure 3: Differentiation of Mesenchymal Stem Cells. Mesenchymal cells after being induced for 15 days. Show positive for $\mathrm{TH}$; a marker for dopaminergic neurons [18].

were isolated from the bone marrow of adult rats and cultured. When these cells were then placed in an induction medium containing IBMX for 2 days they were found to differentiate into neuron-like cells, dopaminergic neuron-like cells as well as adipocytes and chondrocytes. The neuron like cells were found to express surface markers: Nestin, MAP-2a, TH characteristic of neurons at different developmental stages (Figure 3). This showed great potential for the use of mesenchymal stem cells in the treatment of disorders such as PD [18].

A further study, involved isolating NSCs from patients brain. These were then cultured and turned into dopamine-producing neurons. Following this they were put back inside the patient's brain. The results showed reduction in rigidity and trembling. Brain scans revealed that there was a $58 \%$ increase in dopamine production. However, this was found to drop later but symptoms did not return [38].

IPSCs have also shown promising results for the treatment of PD. In one study IPSCs were derived from patients suffering from PD and differentiated into dopaminergic neurons. These cells were then implanted into the striatum of a Parkinsonian rat and were found to reduce motor asymmetry [39].

\section{Huntington's Disease}

Huntington's disease (HD) is an autosomal dominant neurodegenerative disorder. Patients present with uncontrolled jerky movements, in addition to depression and dementia [40]. The disease is due to a mutation in the gene coding for the Huntington protein resulting from CAG repeats [41]. This genetic mutation occurs mostly in the neostriatum causing destruction of GABA-ergic neurons within the putamen and caudate nucleus along with gross atrophy. The deep layers of the cerebral cortex are also affected. These cellular changes explain the chorea (uncontrollable muscle movement) associated with HD [42-44].

This genetic mutation results in the degeneration of GABA-ergic neurons within the caudate-putamen (striatum) and thus explains the chorea (uncontrollable muscle movement) associated with HD [42,43].

\section{Current treatment}

Like with PD there is no definitive treatment for HD. Despite knowing which protein and gene is affected the underlying mechanism is still not known [45]. Rather there are drugs such as anti-depressants and those that suppress movement that help to alleviate the symptoms.

\section{Stem cell treatment}

Research utilizing transplantation of fetal human brain tissue has shown to be successful in reducing cognitive and motor impairments within patient suffering from HD. In one study patients manifesting HD had implants of human fetal striatal tissue put into their brain. When patients were followed up improvements in functional, cognitive and motor abilities were found [45]. The results from this study were consistent with those of a study carried out that same year which also involved grafting of human fetal striated tissue into patients suffering from $\mathrm{HD}$ [42].

Because the tissue being grafted did not go on to develop any mutation this method seemed to offer good hope in replacing the damaged neurons affected by the disease process of HD. However, the limitation of using fetal derived tissue to treat HD is the difficulty in obtaining large amounts of it without overstepping ethical boundaries [9].

Another potential source for treating HD has been through the use of NSCs. These can either be those isolated from embryos or from adults. One study took neural precursor cells that were transplanted into rat models suffering from HD. The neural precursor cells were found to differentiate and when observed expressed antigens characteristic of neurons. This meant that a striatal phenotype had been achieved. The neurons were found to have diffused throughout the brain of the rats [46].

Further studies have been carried out which supports this research. In one study stem cells were obtained from the cortex of human fetuses, which were then transplanted into rats. These rats had been injected with quinolinic acid into their striatum in order to resemble patients suffering from $\mathrm{HD}$. The quinolinic acid being a toxin causes death of the striatum. The results shows that the rats receiving the transplantation had a $22 \%$ increase in their striatal volume when compared to the rats who had been given a sham injection [47].

The positive effects of NSCs are thought to be due to the release of brain derived neurotropic factor (BDNF) released by the NSCs that have been transplanted. Evidence for the positive effects of BDNF also came from a study involving three groups of rats. One group was treated with BDNF, whilst another with beta-galactosidase and a third group who were the control, thus, were not treated with anything. Following this, the three groups were then given lesions of quinolinic acid to mimic the effects of HD. The results showed that the rats treated with BDNF had more cells surviving over the other two groups [43].

The results of this study were supported by a similar experiment carried out the following year where cell lines expressing BDNF were transplanted into the striatum of adult rats. Following this they were injected with quinolinic acid and the cell loss was found to be less than the control group. Other neurotrophins: neurotrophin-3 and neurotrophin- $4 / 5$ showed a decrease in cell loss also but to a lesser extent when compared to BDNF [48]

Transplantation of these cells requires very invasive surgery. A better approach would be to devise a method in which these NSCs could be injected intravenously. This approach was tried on animal models that again were treated with quinolinic acid. Results showed a reduction in the death of striatal neurons when compared to the control [49]. Compared to transplantation, this approach of intravenous injection is much more advantageous due to its less invasive properties. 
In addition to the positive potential shown by NSCs when it comes to treating PD, are IPSCs. In one study IPSCs were derived from the fibroblasts of HD patients. Through homologous recombination the CAG repeat was replaced with a normal repeat. When the IPSCs were then differentiated into neurons, the correction was found to remain. Furthermore, it was found that the phenotypes associated with $\mathrm{HD}$ and the pathogenic signaling pathways were reversed [50].

\section{Alzheimer's Disease}

Alzheimer's disease $(\mathrm{AD})$ is estimated to be the most common type of dementia affecting mainly people over the age of 65 [51]. Causes of $\mathrm{AD}$ are linked to mutations, which leads to increased production of the $\beta$-amyloid peptide. When this peptide forms aggregates it becomes toxic to the brain forming neuritic plaques. Characteristic to Alzheimer patients are also neurofibrillary tangles [52].

Alzheimer's disease (AD) is estimated to be the most common type of dementia affecting mainly people over the age of 65 [51]. Causes of $\mathrm{AD}$ are linked to mutations, which lead to increased production of the B-amyloid peptide. When this peptide aggregates, it forms neuritic plaques that then become toxic to the brain [48]. Characteristic of Alzheimer patients are also neurofibrillary tangles, synpatic deterioration and death of neurons [53]. It is thought that the amyloid plaques affect the activity of the synapse initiating a number of downstream effects leading to dysfunctional interneuronal transmission and inevitably cell death [54].

Evidence shows that Alzheimer patients also suffer from loss of acetylcholine neurons and synapses and therefore reduction in the amount of neurotransmitters released. These neurons are thought to relate to memory, thus loss of them accounts for the manifestation of dementia. Loss of neurons takes place throughout the cortical area, basal forebrain, hippocampus and amygdala $[55,56]$.

\section{Current treatment}

To assist with the management of $\mathrm{AD}$ and aiming to increase the level of neurotransmitter in the brain acetylcholinesterase inhibitors are given to patients. This slows down the breakdown of the neurotransmitter acetylcholine [57]. This treatment is effective in managing the symptoms; however it is not a cure and therefore, shows how necessary the finding of a definitive treatment is.

\section{Stem cell treatment}

Like seen in other neurodegenerative disorders discussed previously: Parkinson's and Huntington's disease, there is evidence also showing that stem cells have a large part to participate in the treatment of AD.

One study showed promise for the use of NSCs derived from ESCs but showed less hope for the use of ESCs alone in their treatment for Alzheimer's. The NSCs derived from ESCs were transplanted into the frontal association cortex of a mouse model of AD.

Results showed that the stem cells survived and went on to differentiate into cholinergic neurons. Memory was also found to improve. The control group who received ESCs alone went on to develop teratomas (Figure 4) [58].

Similar to HD there is evidence showing that the BDNF can help to improve the symptoms of AD. In one study NSCs were transplanted into mouse brains that expressed aggregates of brain plaques and tangles. Results showed that, following transplantation, memory and learning improved. The NSCs were found not to reduce the levels of $\beta$-amyloid levels but rather increase the levels of BDNF, which lead to an increase in the number of synapses [52].

Like with PD and HD, IPSC's have also shown promise in the treatment of AD. Neuronal stem cells were successfully created from the fibroblasts present in adults suffering from PD and healthy individuals. This shows great hope for the use of IPSCs in the treatment of AD [59].

\section{Multiple Sclerosis}

Multiple Sclerosis (MS) is often recognised pathologically by the presence of plaques of inflammatory demyelination. These plaques can be classified into acute, chronic active and chronic silent stages based on their progression of inflammatory destruction. The end stage of these plaques is characteristic of loss of oligodendrocytes and myelin surrounding the axon at the cellular level and scarred hardened areas that can be visualised grossly [60]. This process results in patients presenting with symptoms of numbness and tingling, visual problems and some can experience pain [61].

\section{Current treatment}

As there is currently no treatment for MS there are numerous therapies that have been approved by the FDA which are used to reduce the episodes of symptoms associated with MS (Table 1). Many work in such a way as to moderate the immune system with MS being caused by an inflammatory-mediated process [61]. There is evidence showing immune moderations are an effective treatment but a full functional
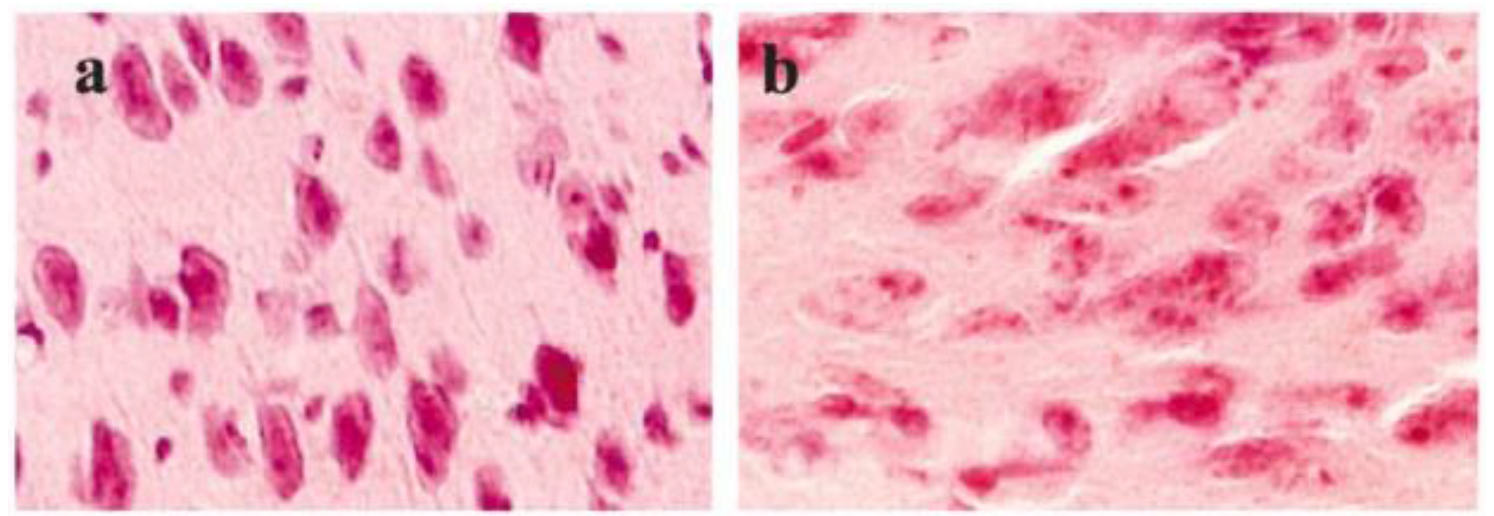

Figure 4: Stain of healthy neurons and teratomas. a) HE stain showing healthy neurons derived from NSC transplantation. b) Teratomas derived from ESC transplantation [58]. 
Citation: Blundell R, Shah M (2015) Neurodegenerative Diseases and Stem Cell Transplantation. J Stem Cell Res Ther 5: 277. doi:10.4172/21577633.1000277

Page 7 of 9

\begin{tabular}{|c|c|c|c|c|}
\hline Drug & Brand (Manufacturer) & Recommended Dose & Dosing Frequency & Route \\
\hline Interferon beta- I a & Avonex (Biogen Idec) & $30 \mathrm{mcg}$ & Once weekly & IM \\
\hline Interferon beta- I a & Rebif (Pfizer) & 22 or $44 \mathrm{mcg}$ & Three times weekly & $S Q$ \\
\hline Interferon beta- I b & Betaseron (Bayer) & $0.25 \mathrm{mg}$ & Every other day & $S Q$ \\
\hline Interferon beta- I b & Extavia (Novartis) & $0.25 \mathrm{mg}$ & Every other day & $S Q$ \\
\hline Glatiramer acetate & Copaxone (Teva) & $20 \mathrm{mg}$ & Once daily & $S Q$ \\
\hline Mitoxantrone & Novantrone (EMD Serono) & 5 to $12 \mathrm{mg} / \mathrm{m}^{2}$ & $\begin{array}{l}\text { Short infusion (about } 5 \text { to } 15 \\
\text { minutes) every } 3 \text { months }\end{array}$ & IV \\
\hline Natalizumab & Tysabri (Biogen Idec) & $300 \mathrm{mg}$ & 1- hour infusion every 4 weeks & IV \\
\hline Fingolimod & Gilenya (Novartis) & $0.5 \mathrm{mg}$ & Once daily & $\mathrm{PO}$ \\
\hline
\end{tabular}

Table 1: FDA-approved drug therapies for Multiple sclerosis [61].

recover in many patients is not witnessed [62]. Furthermore, it seems that these drugs are only able to manage the early relapses that occur MS [63]. Therefore, discovery of another treatment is needed.

\section{Stem cell treatment}

As MS is characterized by loss of myelin and oligodendrocytes finding a way to replace this would serve as a very good treatment. One study utilised shiverer demyelination mutant mice. These were mice that had lesions induced to mimic the characteristics of MS. Fragments of newly born mice were implanted into the brains of the shiverer mice. Results showed there was large amount of myelination over long distances [64], thus showing hope for the treatment of MS. In another study CG4 oligodendrocyte progenitor cells were labelled with blue and grafted into the brains of rat pups that were deficient in myelin. After two weeks, results showed extensive migration, synthesis of myelin components and myelin formation along the axons of various parts of the brain when compared to the control [65]. This showed great hope for a potential treatment in MS.

There is much research looking into the role of ESCs in the treatment of MS. In this study 24 patients made up of 14 women and 10 men were administered ESCs from 4-8 week year old embryos. They were either administered intravenously, subcutaneously or intracavitary. The results shown were promising. $70 \%$ off the patients showed signs of improvements soon after the transplantation. These improvements consisted of decreased weakness and improvement on appetite and mood. Follow up after a month showed reduction in nystagmus, convergence disturbance and spasticity. Improvements in dysarthria, dysphagia, and ataxia were much slower. In general improvements were found in the extremities. There was decrease in tiredness and general weakness, normalization of muscle tone as well as an improvement in the quality of life. $87 \%$ of patients were found to report no worsening or further progression of the disease. An MRI taken 1-2 years after showed a reduction in the focal lesions [38].

More promising than what has been discussed is the role of bone marrow transplants where the patients are their own donors in the treatment of MS. Research indicates that this is the most effective form of treatment. It is thought to work by re-setting the patient's own immune system and having them 'regenerate an antigen-naïve immune system' from their own HSCs $[10,63]$. Patients own HSCs are obtained and stored whilst they undergo intense chemotherapy. Following this, their immune system is regenerated from the HSCs previously stored. Results have shown that patients who experienced severe episodes before treatment, found them to be reduced or completely eliminated following the treatment [66].

NSCs have also found to be useful in the treatment of MS. In

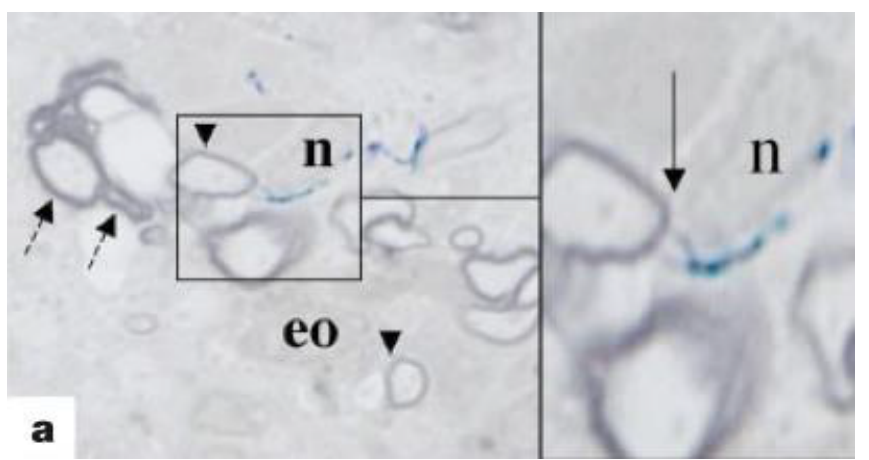

Figure 5: Light microscopy of transplanted neural stem cells. Light microscopy showing transplanted neural stem cells contributing to myelination of axons. ' $n$ ' indicates the nucleus of the neural stem cells, with blue deposits going to surround the axon (arrows) surrounded by myelin (dashed arrows). The short arrowheads represent thin layer of myelin [68].

one study adult NSCs were given to mouse models of MS, either intravenously or intracerebroventricularly. Results showed that these NSCs when administered via either method appeared in areas where demyelination had taken place, and went on to differentiate into mature cells. Axons were also found to be remyelinated (Figure 5) [67].

NSCs in undifferentiated form have also been found to have an anti-inflammatory effect, which provides useful in treating MS with it being a chronic inflammatory mediated process. In one study neural precursor cells were found to cause apoptosis of $\mathrm{T}$ cells causing inflammation of the brain (encephalitis) and further protected against loss off neural tissue [67].

It seems that there are many avenues being explored for the treatment of MS. Autologous bone marrow transplants seem to show much hope. NSCs with their role of protecting against inflammation and ability to replace lost myelin also show great potential.

\section{Conclusion}

Our insight into stem cells has come a long since they were first referred to in the early 1900's and from the evidence being generated it seems there is great potential for future groundbreaking research.

From the current research that has been undertaking it seems there is big role for stem cells to play in the treatment of neurodegenerative disorders. A variety of sources of stem cells: embryonic, bone marrow derived, neural, induced pluripotent and umbilical are showing great hope. However, at the same time each has their limitations. The method chosen therefore when treating neurodegenerative disorders will need to have low side effects associated with it, be cost effective, easily 
Citation: Blundell R, Shah M (2015) Neurodegenerative Diseases and Stem Cell Transplantation. J Stem Cell Res Ther 5: 277. doi:10.4172/21577633.1000277

Page 8 of 9

replicated on a large scale and avoid ethical issues when it comes to obtaining cells.

It was the norm at the time of Ramon y Cajal to believe neurogenesis did not occur. It is exciting to wonder what facts we believe now to be true will be disproved in the future in addition to what other groundbreaking new research will be made, opening the door to future potentialities in treatment of illness and disease.

\section{References}

1. Kumar J, Sharma A, Pattnaik AK, Varadwaj PK (2010) Stem cells: An overview with respect to cardiovascular and renal disease. J Nat Sci Biol Med 1: 43-52. [PubMed]

2. Altman J, Das GD (1965) Autoradiographic and histological evidence of postnatal hippocampal neurogenesis in rats. J Comp Neurol 124: 319-335. [PubMed]

3. Voss HU, Uluc AM, Dyke JP, Watts R, Kobylarz EJ, et al. (2006) Possible axonal regrowth in late recovery from the minimally conscious state. $\mathrm{J}$ Clin Invest 116: 2005-2011. [PubMed]

4. Thomson JA, Itskovitz-Eldor J, Shapiro SS, Waknitz MA, Swiergiel JJ, et al. (1998) Embryonic Stem Cell Lines Derived from Human Blastocysts. Science 282: 1145-1147. [PubMed]

5. Shamblott MJ, Axelman J, Wang S, Bugg EM, Littlefield JW, et al. (1998) Derivation of pluripotent stem cells from cultured human primordial germ cells. Proc Natl Acad Sci USA 95: 13726-13731. [PubMed]

6. Becker AJ, McCulloch EA, Till JE (1963) Cytological Demonstration of the Clonal Nature of Spleen Colonies Derived from Transplanted Mouse Marrow Cells. Nature 197: 452-454. [PubMed]

7. Gatti RA, Meuwissen HJ, Allen HD, Hong R, Good RA (1968) Immunological reconstitution of sex-linked lymphopenic immunological deficiency. Lancet 292: 1366-1369. [PubMed]

8. Maltsev VA, Wombus AM, Rohwedel J, Bader M, Hescheler J (1994) Cardiomyocytes differentiated in vitro from embryonic stem cells developmentally express cardiac-specific genes and ionic currents. Circ Res 74: 233-244. [PubMed]

9. Kim SU, de Vellis J (2009) Stem Cell-Based Cell Therapy in Neurologica Diseases: A Review. J Neurosci Res 87: 2183-2200. [PubMed]

10. Hess DC, Borlongan CV (2008) Stem cells and neurological diseases. Cell Prolif 48: 94-114. [PubMed]

11. Morrison SJ, Shah NM, Anderson DJ (1997) Regulatory Mechanisms in Stem Cell Biology. Cell 88: 287-298. [PubMed]

12. Blundell R, Vassallo J (2013) Neurological Diseases and Stem Cell Transplantation. Stem Cells Technology. Lambert Academic Publishing.

13. Barker RA, Jain M, Armstrong RJE, Caldwell MA (2003) Stem cells and neurological disease. J Neurol Neurosurg Psychiatry 74: 553-557. [PubMed]

14. Sylvester KG, Longaker MT (2004) Stem Cells: review and update. Arch Surg 139: 93-99. [PubMed]

15. McLaren A (2001) Ethical and social considerations of stem cell research Nature 414: 129-131. [PubMed]

16. O'Donoghue K, Fisk NM (2004) Fetal stem cells. Best Pract Res Clin Obste Gynaecol 18: 853-875. [PubMed]

17. Mezey E, Chandross KJ, Harta G, Maki RA, McKercher SR (2000) Turning blood into brain: cells bearing neuronal antigens generated in bib from bone marrow. Science 290: 1778-1182. [PubMed]

18. Guo L, Yin F, Meng H, Ling L, Hu-He T, et al. (2005) Differentiation of Mesenchymal Stem Cells Into Dopaminergic Neuron-like Cells in vitro. Biomed Environ Sci 18: 36-42. [PubMed]

19. Bianco P, Riminucci M, Gronthos S, Robey PG (2001) Bone Marrow Stroma Stem Cells: Nature, Biology, and Potential Applications. Stem Cells 19: 180192. [PubMed]

20. Gunsilius E, Gastl G, Petzer AL (2001) Hematopoietic stem cells. Biomed Pharmacother 55: 186-194. [PubMed]

21. Takahashi K, Yamanaka S (2006) Induction of pluripotent stem cells from mouse embryonic and adult fibroblast cultures by defined factors. Cell 12: 663 676. [PubMed]

22. Blundell R, Agius CM (2013) What are Stem Cells? Stem Cells Technology Lambert Academic Publishing.

23. Blundell R, Kleinbloesem CH (2013) Stem cells therapies - a new era in therapeutic techniques and applications in patients with no other treatment options. Stem Cells Technology. Lambert Academic Publishing.

24. Temple S (2001) The development of neural stem cells. Nature 414: 112-117. [PubMed]

25. Eriksen JL, Dawson TM, Dickson DW, Petrucelli L (2003) Caught in the Act: alpha-Synuclein Is the Culprit in Parkinson's Disease. Neuron 40: 453-456. [PubMed]

26. Fahn S (2003) Description of Parkinson's disease as a clinical syndrome. Ann N Y Acad Sci 991: 1-14. [PubMed]

27. Kim JH, Auerbach JM, Rodriguez-Gomez JA, Velasco I, Gavin D, et al (2002) Dopamine neurons derived from embryonic stem cells function in an animal model of Parkinson's disease. Nature 418: 50-56. [PubMed]

28. Hamani C, Lozano AM (2003) Physiology and Pathophysiology of Parkinson's Disease. Ann N Y Acad Sci 991: 15-21. [PubMed]

29. Braak H, Del Tredici K, Rub U, de Vos RA, Jansen Steur EN, et al. (2003) Staging of brain pathology related to sporadic Parkinson's disease. Neurobio Aging 24: 197-211. [PubMed]

30. Perlmutter JS, Mink JW (2006) Deep Brain Stimulation. Annu Rev Neurosci 29 229-257. [PubMed]

31. Lindvall O, Widner $H$, Rehncrona S, Brundin P, Odin P, et al. (1992 Transplantation of fetal dopamine neurons in Parkinson's disease: one-year clinical and neurophysiological observations in two patients with putaminal implants. Ann Neurol 31: 155-165. [PubMed]

32. Hauser RA, Freeman TB, Snow BJ, Nauert M, Gauger L, et al. (1999) Long term evaluation of blateral fetal nigral transplantation in Parkinson's disease. Arch Neurol 56: 179-187. [PubMed]

33. Olanow CW, Goetz CG, Kordower JH, Stoessl AJ, Sossi V, et al. (2003) A double-blind controlled trial of bilateral fetal nigral transplantation in Parkinson's disease. Ann Neurol 54: 403-414. [PubMed]

34. Sanberg PR (2007) Neural stem cells for Parkinson's disease: To protect and repair. PNAS 104: 11869-11870. [PubMed]

35. Lee SH, Lumelsky N, Studer L, Auerback JM, McKay RD (2000) Efficient generation of midbrain and hindbrain neurons from mouse embryonic stem cells. Nat Biotechnol 18: 675-679. [PubMed]

36. Zhang SC, Wernig M, Duncan ID, Brustle O, Thomson JA (2001) In vitro differentiation of transplantable neural precursors from human embryonic stem cells. Nat Biotechnol 19: 1129-1133. [PubMed]

37. Freed CR, Greene PE, Breeze RE, Tsai W, DuMouchel W, et al. (2001) Transplantation of Embryonic Dopamine Neurons for severe Parkinson's Disease. N Engl J Med 344: 710-719. [PubMed]

38. UI Hassan A, Hassan G, Rasool Z (2009) Role of Stem Cells in Treatment of Neurological Disorder. Int J Health Sci (Qassim) 3: 227-233. [PubMed]

39. Hargus G, Cooper O, Deleidi M, Levy A, Lee K, et al. (2010) Differentiated Parkinson patient-derived induced pluripotent stem cells grow in the adult rodent brain and reduce motor asymmetry in Parkinsonian rats. Proc Natl Acad Sci USA 107: 15921-15926. [PubMed]

40. Zuccato C, Valenza M, Cattaneo E (2010) Molecular Mechanisms and Potential Therapeutical Targets in Huntington's Disease. Physiol Rev 90: 905-981. [PubMed]

41. HD Collaborative Research Group (1993) A novel gene containing trinucleotide repeat that is expanded and unstable on Huntington's disease chromosomes. Cell 72: 971-983. [PubMed]

42. Freeman TB, Cicchetti F, Hauser RA, Deacon TW, Li X, et al. (2000) Transplanted fetal striatum in Huntington's disease: Phenotypic developmen and lack of pathology. Proc Natl Acad Sci USA 97: 13877-13882. [PubMed]

43. Bemelmans AP, Horellou P, Pradier L, Brunet I, Colin P, et al. (1999) Brainderived neurotrophic factor-mediated protection of striatal neurons in an excitotoxic rat model of Huntington's disease, as demonstrated by adenoviral gene transfer. Hum Gene Ther 10: 2987-2997. [PubMed] 
Citation: Blundell R, Shah M (2015) Neurodegenerative Diseases and Stem Cell Transplantation. J Stem Cell Res Ther 5: 277. doi:10.4172/21577633.1000277

\section{Huntington G (1872) On chorea. Med Surg Report 26: 320.}

45. Bachoud-Levi AC, Remy P, Nguyen JP, Brugieres P, Lefaucheur JP, et al. (2000) Motor and cognitive improvements in patients with Hunting- ton's disease after neural transplantation. Lancet 356: 1975-1979. [PubMed]

46. Armstrong RJ, Watts C, Svendsen CN, Dunnett SB, Rosser AE (2000) Survival, neuronal differentiation, and fiber outgrowth of propagated human neural precursor grafts in an animal model of Huntington's disease. Cell Transplant 9: 55-64. [PubMed]

47. McBride JL, Behrstock SP, Chen EY, Jakel RJ, Siegel I, et al. (2004) Human neural stem cell transplants improve motor function in a rat model of Huntington's disease. J Comp Neurol 475: 211-219. [PubMed]

48. Perez-Navarro E, Canudas AM, Akerund P, Alberch J, Arenas E (2000) Brainderived neurotrophic factor, NT-3 and NT-3/4 prevent the death of striatal projection neurons in rodent model of Huntington's disease. J Neurochem 75 : 2190-2199. [PubMed]

49. Lee ST, Chu K, Park J, Lee K, Kang L, et al. (2005) Intravenous administration of human neural stem cells induces functional recovery in Huntington's disease rat model. Neurosci Res 52: 243-249. [PubMed]

50. An MC, Zhang N, Scott G, Montoro D, Wittkop T, et al. (2012) Genetic correction of Huntington's Disease Phenotypes in Induced Pluripotent Stem Cells. Cell Stem Cell 11: 253-263. [PubMed]

51. Salawu FK, Umar JT, Olokoba AB (2011) Alzheimer's disease: a review of recent developments. Ann Afr Med 10: 73-79. [PubMed]

52. Blurton-Jones M, Kitazawa M, Martinez-Coria H, Castello NA, Muller FJ, et al. (2009) Neural stem cells improve cognition via BDNF in a transgenic model of Alzheimer disease. Proc Natl Acad Sci USA 106: 13594-13599. [PubMed]

53. Alzheimer A, Stelzmann RA, Schnitzlein HN, Murtagh FR (1995) An English translation of Alzheimer's 1907 paper, "Über eine eigenartige Erkankung der Hirnrinde." Clin Anat 8: 429-431. [PubMed]

54. Ballard C, Gauthier S, Corbett A, Brayne C, Aarsland D, et al. (2011) Alzheimer's disease. Lancet 377: 1019-1031. [PubMed]

55. Cummings JL, Vinter HV, Cole GM, Khachaturian ZS (1998) Alzheimer's disease: etiologies, pathophysiology, cognitive reserve, and treatment opportunities. Neurology 51: S2-17. [PubMed]

56. Coyle JT, Price DL, DeLong MR (1983) Alzheimer's disease: a disorder of cortical cholinergic innervation. Science 219: 1184-1190. [PubMed]

57. Birks J (2006) Cholinesterase inhibitors for Alzheimer's disease. Cochrane Database Syst Rev 25: CD005593. [PubMed]

58. Wang Q, Matsumoto Y, Shindo T, Miyake K, Shindo A, et al. (2006) Neural stem cells transplantation in cortex in a mouse model of Alzheimer's disease. J Med Invest 53: 61-69. [PubMed]

59. Qiang L, Fujita R, Yamashita T, Angulo S, Rhinn H, et al. (2011) Directed conversion of Alzheimer's disease patient skin fibroblasts into functional neurons. Cell 146: 359-371. [PubMed]

60. Wu GF, Alvarez E (2011) The immuno-pathophysiology of multiple sclerosis Neurol Clin 29: 257-278. [PubMed]

61. Goldenberg M (2012) Multiple Sclerosis Review. PT 37: 175-184. [PubMed]

62. Paty D, Ebers GC (1998) Multiple sclerosis. F.A. Davis, Philadelphia.

63. Karussis D, Petroud P, Vourka-Karussis U, Kassis I (2013) Hematopoietic stem cell transplantation in multiple sclerosis. Expert Rev Neurother 13: 567-578. [PubMed]

64. Lachapelle F, Gumpel M, Baulac C, Jacque C (1983) Transplantation of fragments of CNS into the brain of shiverer mutant mice: extensive myelination of transplanted oligodendrocytes. Dev Neurosci 6: 326-334. [PubMed]

65. Espinosa de los Monteros A, Zhao P, Huang C, Pan T, Chang R, et al. (1997) Transplantation of CG4 oligodendrocyte progenitor cells in the myelin-deficient rat brain results in myelination of axons and enhanced oligodendroglial markers. J Neurosci Res 50: 872-887. [PubMed]

66. Atkins HL, Freedman MS (2013) Hematopoietic Stem Cell Therapy for Multiple Sclerosis: Top 10 Lessons Learned. Neurotherapeutics 10: 68-76. [PubMed]

67. Pluchino S, Zanotti L, Rossi B, Brambilla E, Ottoboni L, et al. (2005) Neurosphere-derived multipotent precursors promote neuroprotection by an immunomodulatory mechanism. Nature 436: 266-271. [PubMed] 